\title{
Сподумен - основной источник лития редкометалльных пегматитов Колмозерского месторождения
}

\author{
Морозова Л.Н., Базай А.В. \\ Геологический институт КНЦ РАН, Anamumbl, morozova@geoksc.apatity.ru
}

Аннотация. Сподумен из пегматитов Колмозерского литиевого месторождения представлен тремя генерациями. Сподумен первой, второй и третьей генерации сопоставимы между собой по химическому составу. В сподумене-І и сподумене-ІІ была установлена внутрифазовая неоднородность Внутрифазовая неоднородность проявлена в наличии зон (участков) с высокой и низкой величиной отношения Fe/Mn (10.75-17.57 и 4.63-9.80 соответственно). Методом масс-спектроскопии с индуктивно связанной плазмой (ICP-MS) в составе сподумена-ІІ из редкометалльных пегматитов Колмозерского литиевого месторождения было определено содержание редких элементов: Be, Ta, Nb, Cs, Rb, Mn, Ti, Hf, Sr, Ba, Tl, Pb, Th, U, Y, Zr, Zn, Sc, V, Cr, Co, Ni, $\mathrm{Cu}, \mathrm{Ga}, \mathrm{Ge}, \mathrm{As}, \mathrm{Cd}, \mathrm{Sn}, \mathrm{Bi}$. Отличительной особенностью состава сподумена-ІІ являются высокие содержания (ppm) Mn (993.20), Rb (1673.58), Ti (95.20), Bi (85.76), Cu (78.21), Ga (56.36), Sn (55.18), Zn (46.07), Cr (22.16), $\mathrm{Nb}$ (10.04). Наличие в составе сподумена-ІІ многочисленных элементов примесей, в большинстве случаев, обусловлено многочисленными минеральными включениями. Содержание лития в сподумене-II, определенное методом ICP-MS, составило 36068.53 ppm, что при пересчете на $\mathrm{Li}_{2} \mathrm{O}$ составляет 7.77 мас. \%.

Ключевые слова: редкометалльные пегматиты, Кольский полуостров, Колмозерское литиевое месторождение, сподумен, литий.

\section{Spodumene - main $\mathrm{Li}$ source in the rare-metal pegmatites from the Kolmozero deposit}

\author{
Morozova L.N., Bazai A.V. \\ Geological Institute KSC RAS, Apatity,morozova@geoksc.apatity.ru
}

\begin{abstract}
Spodumene in the the rare-metal pegmatites from the Kolmozero lithium is represented by three generations. Spodumen-I, II, III have the same chemical composition. Intraphase heterogeneity of spodumene-I and spodumene-II was identified. Intraphase heterogeneity is manifested in the presence of zones (sections) with high and low values of the Fe/Mn ratio (10.75-17.57 and 4.63-9.80, respectively). The content of rare elements: $\mathrm{Be}, \mathrm{Ta}, \mathrm{Nb}$, Cs, Rb, Mn, Ti, Hf, Sr, Ba, Tl, Pb, Th, U, Y, Zr, Zn, Sc, V, Cr, Co, Ni, Cu, Ga, Ge, As, Cd, Sn, Bi in spodumene-II from rare metal pegmatites of the Kolmozero lithium deposit was determined by mass spectroscopy method with inductively coupled plasma (ICP-MS). The distinctive feature of the spodumene composition is a high content (ppm) of Mn (993.20), Rb (1673.58), Ti (95.20), Bi (85.76), Cu (78.21), Ga (56.36), Sn (55.18), Zn (46.07), Cr (22.16), $\mathrm{Nb}$ (10.04). The presence of numerous impurity elements in the spodumene composition, in most cases, is due to numerous mineral inclusions. The lithium content in spodumene, determined by the ICP-MS method, amounted to 36068.53 ppm, which in terms of $\mathrm{Li}_{2} \mathrm{O}$ is 7.77 wt. \%
\end{abstract}

Key words: rare-metal pegmatites, Kola Peninsula, Kolmozero lithium deposit, spodumene, lithium.

\section{Введение}

Сподумен является одним из основных минералов, который применяется как промышленное сырье для получения лития, а также для производства керамики. Сподумен встречается преимущественно в гранитных пегматитах. Кроме сподумена в гранитных пегматитах отмечаются и другие литиевые минералы, в частности петалит, трифилин-литиофилит, лепидолит, амблигонит и др.

Широко распространен сподумен в редкометалльных пегматитах Колмозерского редкометалльного пегматитового пояса (рис. 1). В литиевых месторождениях Колмозерское и Полмостундровское содержание сподумена составляет 20 \% от общего объема жил. Сподумен в жилах редкометалльных пегматитов месторождения Васин-Мыльк (Cs) и Охмыльк (Cs-Тa) распределен в неравномерно, и поэтому рассматривается как попутное сырье для получения лития.

Как показали полевые исследования, размеры сподумена, его цвет и формы выделения достаточно разнообразны (рис. 1, 2). Например, в редкометалльных пегматитах Полмостундровско- 


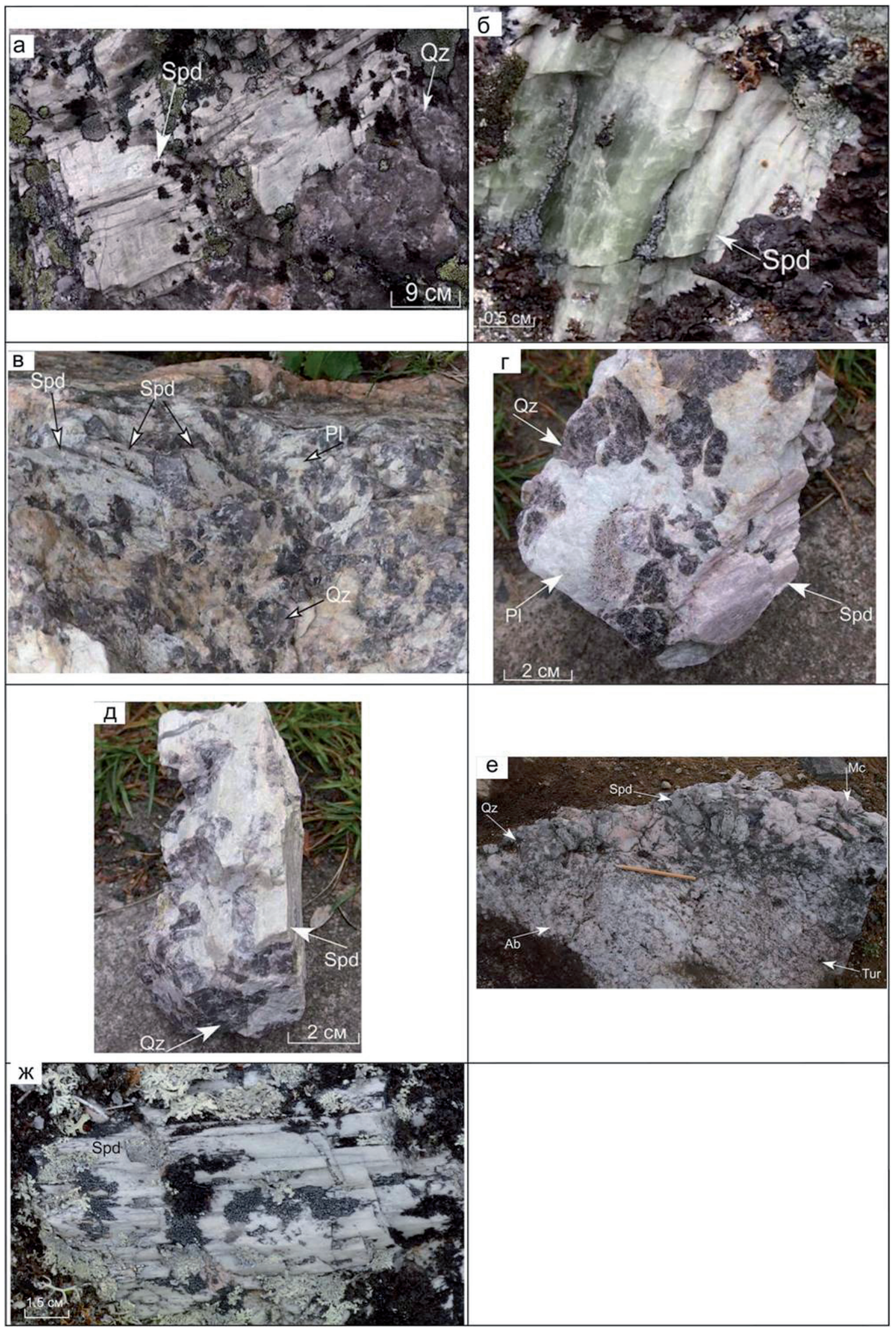

Рис. 1. Сподумен из пегматитов Колмозерского редкометалльного пегматитового пояса.

а, б - месторождение Полмостундровское; в, г, д-месторождение Васин-Мыльк; е-месторождение Охмыльк; д - рудопроявление Солдат-Мыльк.

Fig. 1. Spodumene (Spd) in pegmatites of the Kola Rare Metal Pegmatites Belt.

a, 6 - Polmostundra deposit; в, г, Д - Vasin-Mylk deposit; e - Okhmylk deposit; ж - Soldier-Mylk Spd - spodumene; $\mathrm{Pl}(\mathrm{Ab})$ - plagioclase (albite); Qz - quartz; Mc - microcline; Tur -tourmaline. 
го месторождения отмечаются непрозрачные кристаллы сподумена, неравномерно окрашенные в серовато-зеленоватый цвет (рис. 1 a), и полупрозрачные сподумены, неравномерно окрашенные в зеленый и белый цвет (рис. 1 б). В редкометалльных пегматитах месторождения Васин-Мыльк цвет сподумена - зеленоватый, розовый и белый (рис. 1 в, 1 г, 1 д). В редкометалльных пегматитах рудопроявления Солдат-Мыльк цвет сподумена - от серовато-зеленоватого до белого. В данной статье приводятся результаты изучения сподумена из редкометалльных пегматитов Колмозерского литиевого месторождения.

\section{Результаты исследований}

Сподумен из редкометалльных пегматитов Колмозерского литиевого месторождения (Гордиенко, 1970; Морозова, 2018; Morozova, 2019; Морозова, 2019) представлен тремя генерациями (Морозова, Базай, 2019 a; Морозова, Базай, 2019 б). Сподумен первой генерации (Spd-I) отмечается в виде кристаллов уплощенно-призматического облика, минерал серовато-зеленоватого цвета, непрозрачный. Распространен фрагментарно на участках развития блокового микроклин-пертита-I (рис. 2 а). Среди твердофазных (минеральных) включений в Spd-I диагностированы альбит, кварц, мусковит, микроклин. Редко отмечаются включения минералов группы колумбита

Сподумен второй генерации (Spd-II) распространен в центральной части жил пегматитов. Кристаллы Spd-II уплощенно-призматического габитуса - от коротко- до длинно-призматических. Наблюдаются как единичные кристаллы сподумена, так и их скопления. Размеры индивидов могут достигать 1.5 м в длину. Минерал серовато-зеленоватый, непрозрачный. В единичных случаях отмечается полупрозрачный сподумен зеленого цвета (рис. 2 в). Наблюдаются деформированные

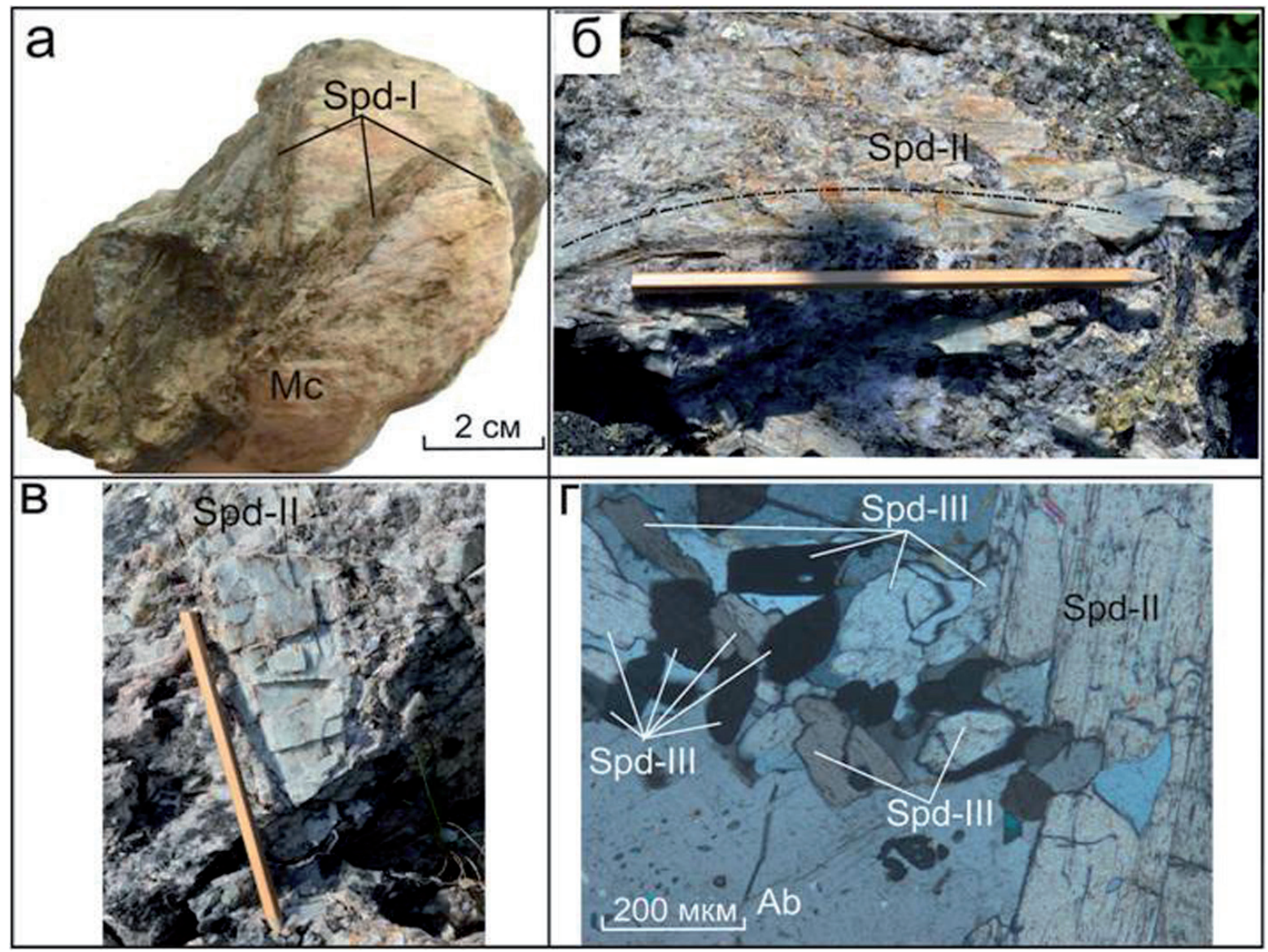

Рис. 2. Сподумен из редкометалльных пегматитов Колмозерского литиевого месторождения. a - сподумен-I; б, в - сподумен-II; г- сподумен-III.

Fig. 2. Spodumene (Spd) in rare metal pegmatites of the Kolmozero lithium deposit. a - spodumene -I; б, в - spodumene -II; $\Gamma$-spodumene -III. 


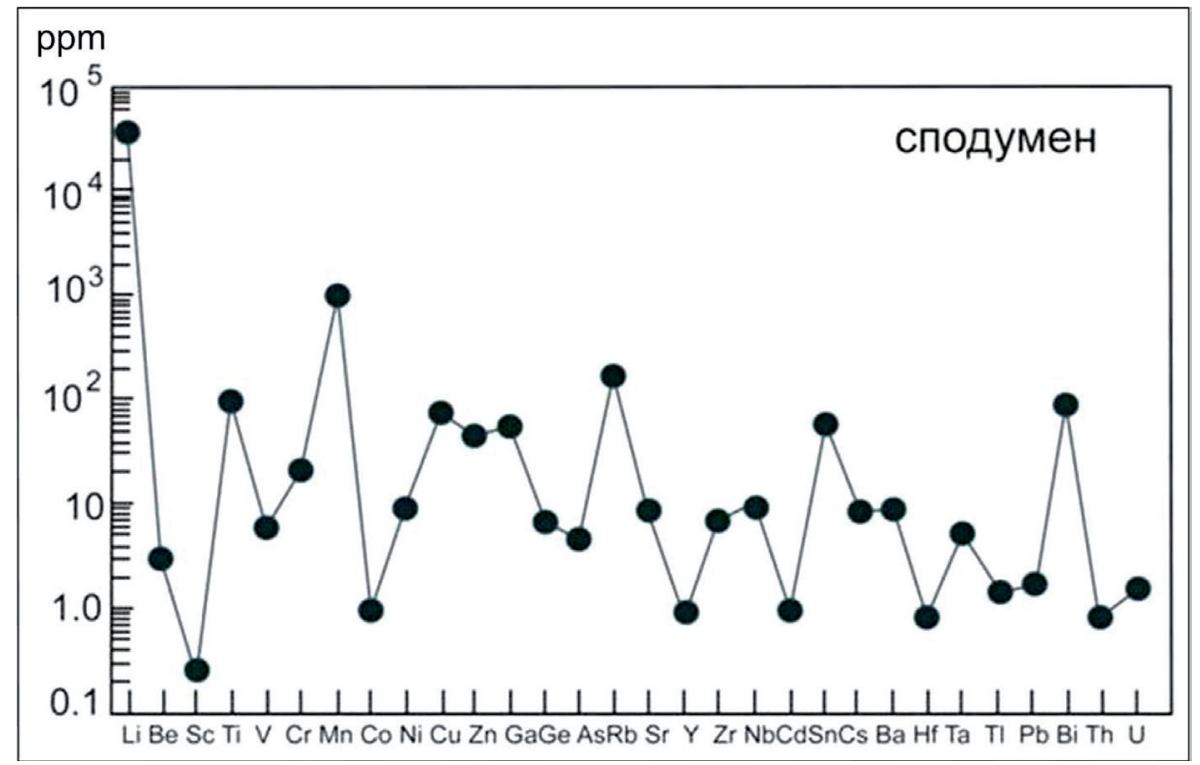

Рис. 3. Распределение редких элементов в сподумене из редкометалльных пегматитов Колмозерского месторождения (Morozova et al., 2019).

Fig. 3. Rare elements distribution in spodumene of rare-metal pegmatites from the Kolmozero lithium deposit (Morozova et al., 2019).

(изогнутые) кристаллы сподумена (рис. 2 б). Сподумен второй генерации содержит включения альбита, кварца, мусковита, касситерита, минералов группы колумбита, апатита и граната.

Сподумен третьей генерации представлен кристаллами короткопризматического или изометричного облика размером до 0.5 мм. Сподумен-III, распространенный в мелкозернистой кварцсподумен-полевошпатовой массе (рис. 2 г), был диагностирован при изучении минерала в прозрачных шлифах. Сподумен третьей генерации включений не содержит.

Результаты анализов показали, что составы сподуменов разных генераций, изученных микрозондовым методом, близки между собой. В качестве элементов-примесей микрозондовым методом в минералах трех генераций были определены Fe, Mn, Rb и $\mathrm{Na}$. Кристаллохимические формулы сподумена близки к идеальной $-\mathrm{LiAlSi}_{2} \mathrm{O}_{6}$.

Состав наиболее распространенного сподумена-II был изучен стандартным химическим анализом и методом масс-спектроскопии с индуктивно связанной плазмой ICP-MS (Morozova et al., 2019). Очищение сподумена-ІІ от примесей не проводилось.

Содержание лития в сподумене, определенное методом ICP-MS, составило 36068.53 ppm (рис. 3), что при пересчете на $\mathrm{Li}_{2} \mathrm{O}$ составляет 7.77 мас. \%. Содержание $\mathrm{Li}_{2} \mathrm{O}$, определенное химическим анализом в таком же сподумене варьирует от 7.11 до 8.08 мас. \%. Таким образом, различными методами получены сопоставимые содержания лития в изученном сподумене.

Проведенные расчеты показали, что на сподумен приходится 96 \% лития от его общего содержания в изученных редкометалльных пегматитах Колмозерского месторождения, на плагиоклаз $-0.85 \%$, на калиевый полевой шпат $-0.26 \%$, а на мусковит $-1.88 \%$.

Анализ распределения редких элементов показал, что в сподумене-II в качестве элементовпримесей наблюдаются: Be, Ta, Nb, Cs, Rb, Mn, Ti, Hf, Sr, Ba, Tl, Pb, Th, U, Y, Zr, Zn, Sc, V, Cr, Co, $\mathrm{Ni}, \mathrm{Cu}, \mathrm{Ga}, \mathrm{Ge}, \mathrm{As}, \mathrm{Cd}, \mathrm{Sn}, \mathrm{Bi}$. Наиболее высокие содержания отмечаются (ppm) для Mn (993.20), Rb (1673.58), Ti (95.20), Bi (85.76), Cu (78.21), Ga (56.36), Sn (55.18), Zn (46.07), Cr (22.16), Nb (10.04). Более низкие содержания имеют (ppm) Be (2.94), V (5.97), Pb (1.70), U (1.61), Cs (8.36), Ba (9.37), Ta (5.26), Tl (1.49), Ge (7.28), As (4.43), Sr (8.63), Zr (7,11), Gd (1.03). Содержание Sc, Co, Y, Hf, Th, составляет менее 1 ррm.

Наличие в составе сподумена-ІІ многочисленных элементов-примесей, в большинстве случаев, обусловлено многочисленными минеральными включениями в минерале. 
График распределения редкоземельных элементов для сподумена-II, нормированный на хондрит, характеризуется умеренно дифференцированным спектром $\left((\mathrm{La} / \mathrm{Yb})_{\mathrm{N}}=7.53\right)$ с отрицательной Еu-аномалией $\left(\mathrm{Eu} / \mathrm{Eu}^{*}=0.41\right)$. Суммарное содержание РЗЭ в сподумене-ІІ составляет $4.07 \mathrm{ppm}$, что выше, чем в Ab-II, Mc-II и мусковите из пегматитов Колмозерского месторождения.

При изучении минерала была выявлена внутрифазовая неоднородность сподумена первой и второй генерации. Внутрифазовая неоднородность проявлена в наличии участков (зон) разных оттенков серого на BSE изображениях, различающихся по химическому составу. Было установлено, что более светлые зоны по сравнению с темными характеризуются боле высокой величиной отношения $\mathrm{Fe} / \mathrm{Mn}$ (10.75-17.57 и 4.63-9.80 мас. \% соответственно). Центральные части однородных индивидов Spd-II по составу близки к составам зон в неоднородных индивидах Spd-II с высоким отношением $\mathrm{Fe} / \mathrm{Mn}$.

На основании полученных результатов можно сделать вывод о том, что сингенетическая внутрифазовая неоднородность сподумена из редкометалльных пегматитов Колмозерского литиевого месторождения является результатом изменения физико-химических условий минералообразования в процессе эволюции пегматитового процесса и обусловлена изоморфным замещением лития такими элементами-примесями как железо и марганец. Содержание лития в сподумене, определенное методом ICP-MS, составило 36068.53 ppm, что при пересчете на $\mathrm{Li}_{2} \mathrm{O}$ составляет 7.77 мас. \%

\section{Благодарность}

Авторы выражают благодарность OOO «ТД HALMEK-LITHIUM» и Т.Б. Баяновой за организацию полевых работ.

Исследования выполнены в рамках темы НИР № 0226-2019-0053.

\section{Литература}

1. Гордиенко В.В. Минералогия, геохимия и генезис сподуменовых пегматитов. Л. Изд-во: Недра. 1970. $240 \mathrm{c}$.

2. Морозова Л.Н. Колмозерское литиевое месторождение редкометалльных пегматитов: новые данные по редкоэлементному составу (Кольский полуостров) // Литосфера. 2018. Т. 18. № 1. С. 82-98. DOI: 10.24930/1681-9004-2018-18-1-082-098.

3. Морозова Л.Н., Базай А.В. Сподумен из редкометалльных пегматитов Колмозерского литиевого месторождения (Кольский полуостров) // Записки Российского минералогического общества. 2019 а. Т. 148. № 1. C. 65-78. DOI:10.30695/zrmo/2019.1481.06.

4. Морозова Л.Н. Геохимия редких элементов редкометалльных пегматитов Колмозерского пегматитового поля (Кольский полуостров) // Физико-химические и петрофизические исследования в науках о земле. М. Изд-во: ФГБУН ИГЕМ РАН. 2019. С. 248-251.

5. Морозова Л.Н., Базай А.В. Геохимия редких элементов и состав породообразующих минералов редкометалльных пегматитов Колмозерского литиевого месторождения (Кольский полуостров) // Геодинамическая эволюция литосферы Центрально-Азиатского подвижного пояса (от океана к континенту). Материалы совещания. Вып. 17. Иркутск: Институт земной коры СО РАН. 2019 б. С. 183-185.

6. Morozova L.N. The Kolmozero deposit: a unique Li source in the European Arctic of Russia // IOP Conference Series Earth and Environmental Science. 2019. V. 302. № 1. 012047. DOI: 10.1088/1755-1315/302/1/012047

7. Morozova L.N., Batalin G.A., Gareev B.I., Trifonov A.A. Rare elements in minerals of pegmatites of the Kolmozero deposit (Kola Peninsula) // IOP Conference Series: Earth and Environmental Science. 2019. V. 302. № 1. 012048. DOI: $10.1088 / 1755-1315 / 302 / 1 / 012048$. 